\title{
PENGGUNAAN HISTOGRAM DARI KOEFISIEN APROKSIMASI WAVELET UNTUK DETEKSI CACAT TEKSTIL
}

\author{
Fitri Arnia ${ }^{1,2}$, Andika Saputra ${ }^{1}$, dan Khairul Munadi ${ }^{1,2}$ \\ ${ }^{1}$ Jurusan Teknik Elektro, Fakultas Teknik \\ ${ }^{2}$ Program Magister Teknik Elektro, Program Pasca Sarjana \\ Universitas Syiah Kuala
}

\begin{abstract}
ABSTRAK - Pada industri tekstil, cacat produksi umumnya masih diperiksa secara manual oleh manusia. Pemeriksaan secara manual rentan terhadap kesalahan dan kurang konsisten, karena sifat manusia yang dapat lelah, lupa dan lain sebagainya. Untuk menjamin konsistensi dan kualitas pemeriksaan cacat kain, sebuah sistem deteksi otomatis perlu ada. Penelitian ini mengusulkan penggunaan histogram dari koefisien aproksimasi wavelet dua tingkat sebagai fitur untuk deteksi cacat tekstil. Jarak Euclidian yang dihitung diantara fitur tekstil citra referensi (berasal dari citra tidak cacat) dengan fitur tesktil citra cacat digunakan sebagai parameter evaluasi. Jika jarak Euclidian dari fitur suatu citra tekstil berada di atas nilai ambang yang telah ditentukan sebelumnya, citra tersebut dinyatakan cacat, dan sebaliknya. Penelitian dilaksanakan dengan menjalankan simulasi deteksi cacat tekstil, menggunakan empat kelompok cacat tekstil yang berbeda. Ditemukan bahwa metode usulan mencapai tingkat kebenaran deteksi sebesar 100\% untuk citra kelompok cacat tinta dan kelompok cacat lubang.
\end{abstract}

Kata Kunci : Histogram koefisien wavelet, Jarak Euclidean, Cacat tekstil, Industri tekstil, Fitur citra

\begin{abstract}
Generally, textile defect inspection at textile industry is still conducted manually by human. This approach is susceptible to errors and tends to be inconsistent due to fatigue and inattentiveness. To guarantee the consistency and inspection quality, an automatic defect detection system is required. This research proposes the use of histograms generated from two-level wavelet's approximation coefficients as features to detect textile defects. The Euclidian distance that is calculated between feature of reference textile (non-defective textile) and feature of defective one is used as an evaluation parameter. If the Euclidian distances of the features of textile images are higher than a predetermined threshold, the textiles are determined as defective ones, and vice versa. Simulations are conducted using four groups of textile defects. It turns out that the proposed method can achieve $100 \%$ detection rate for textile group with ink-spot and textile group with holes.
\end{abstract}

Keywords : Wavelet coefficient histogram, Euclidean distance, Textile defect, industrial textiles, Image features

\section{PENDAHULUAN}

Pemeriksaan cacat pada industri tekstil umumnya masih dilakukan oleh manusia. Peme- riksaan seperti ini rentan terhadap kesalahan dan kurang konsisten karena sifat manusia yang dapat lelah, lupa dan lain sebagainya. Untuk menjamin konsistensi dan kualitas pemeriksaan cacat kain, sebuah sistem deteksi otomatis yang dilakukan mesin (komputer) perlu ada.

Selama lebih dari dua puluh tahun terakhir, banyak algoritma yang telah dikembangkan untuk deteksi cacat tekstil secara otomatis. Secara garis besar, dasar pengembangan algoritma-algoritma tersebut dibagi menjadi tujuh bagian yaitu sta- tistikal, spektral, model, learning, stuktural, hybrid dan berbasis motif [1]. Algoritma deteksi yang dikembangkan berdasarkan informasi spektral bia- sanya menggunakan transformasi Fourier, wavelet dan wavelet Gabor untuk mendapatkan fitur dari tekstil. Fitur merupakan substansi penting dalam suatu sistem deteksi, karena pemilihan fitur yang sesuai dapat meningkatkan keberhasilan deteksi.

Penelitian ini mengusulkan penggunaan his- togram dari koefisien aproksimasi wavelet dua ting- kat sebagai fitur tekstil, yang selanjutnya digunakan untuk mendeteksi cacat 


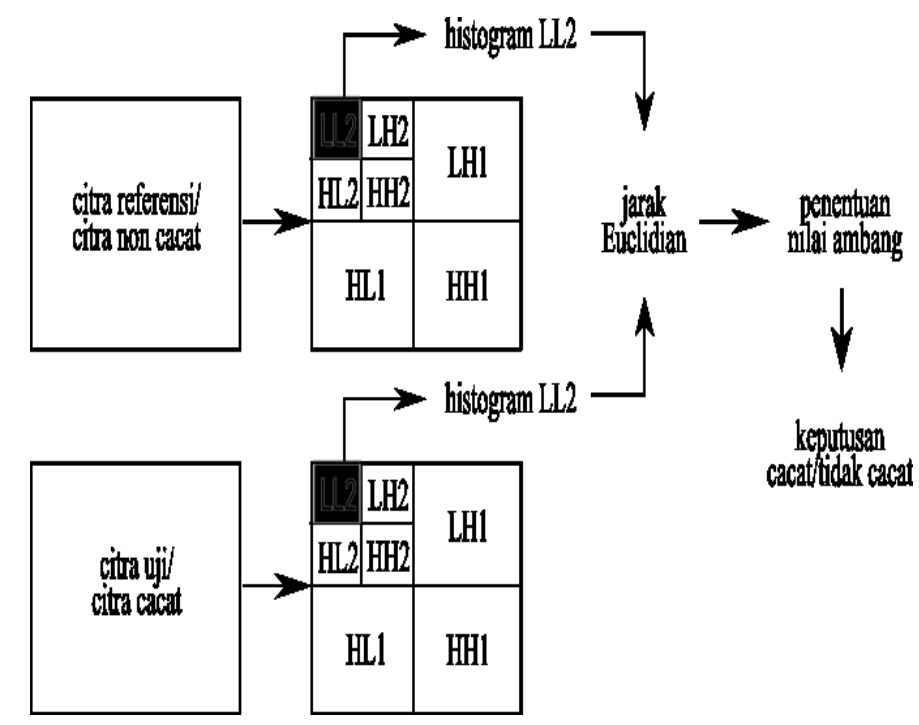

Gambar 1. Diagram blok metode usulan deteksi cacat tekstil dengan histogram LL2

tekstil. Jarak Euclidian yang dihi- tung antara fitur tekstil referensi (berasal dari citra tidak cacat) dengan fitur tesktil cacat digunakan sebagai parameter evaluasi. Jika jarak suatu citra tekstil berada di atas nilai ambang yang telah ditentukan sebelumnya, citra tersebut dinyatakan cacat, dan sebaliknya. Hasil simulasi menggunakan citra pada basis data TILDA [2] menunjukkan bahwa metode usulan mencapai rate deteksi sebesar 100\% untuk tekstil dengan cacat tinta dan cacat lubang

\section{TINJAUAN PUSTAKA}

Selama dua puluh tahun terakhir, telah banyak algoritma deteksi cacat tekstil yang dikembangkan. Algoritma-algoritma tersebut pada dasarnya dapat dikelompokkan menjadi tujuh jenis; statistikal, spektral, model, learning, stuktural, hybrid dan berbasis motif [1][3]. Algoritma yang dikembang- kan pada domain spektral, secara alamiah memiliki kesesuaian untuk deteksi cacat tekstil, karena tekstil umumnya terdiri dari pola yang berulang-ulang, yang memungkinkan penggunaan komponen spek- tral untuk mendeteksi adanya kecacatan [1]. Algo- ritma domain spektral umumnya menggunakan transformasi Fourier, wavelet dan Gabor.
Transformasi Fourier menganalisis suatu sinyal menjadi sekumpulan gelombang sinusoidal dengan frekuensi dan amplitude berbeda. Transformasi ini bisa digunakan untuk mengetahui kandungan fre- kuensi suatu sinyal, namun tidak bisa memberikan informasi tentang saat frekuensi itu muncul. Trans- formasi wavelet adalah fungsi matematika yang mendekomposisi suatu citra menjadi beberapa kom- ponen yang memiliki skala dan posisi pergeseran yang berbeda. Transformasi ini berbasiskan gelom- bang kecil (karena itu disebut wavelet) yang waktu kemunculannya terbatas. Tidak seperti transformasi Fourier, dengan transformasi wavelet kita bisa mengetahui frekeuensi apa yang terkandung pada sinyal, dan waktu frekuensi itu muncul [4].

Pada dasarnya filter-filter Gabor adalah sekum- pulan wavelet, dengan setiap waveletnya merep- resentasikan energi dari suatu frekuensi dengan arah atau orientasi khusus. Karena itu, proses per- hitungan fitur yang berasal dari filter Gabor jauh lebih banyak dan rumit jika dibandingkan dengan proses yang diperlukan wavelet [5].

Transformasi Fourier menghasilkan fitur yang sesuai untuk deteksi cacat global seperti abrasion (rusak akibat gesekan) dan penyusutan tekstil. Namun, cacat-cacat yang sifatnya setempat hanya bisa dideteksi oleh wavelet dan Gabor [5]. Chan, dkk. 
menggunakan tujuh parameter yang diturunkan dari spektrum frekuensi transformasi Fourier untuk deteksi cacat tekstil. Mereka mengevaluasi algoritma usulannya pada tekstil dengan empat jenis cacat. Hasil simulasi menun- jukkan bahwa ketujuh parameter tersebut dapat mengelompokkan jenis-jenis cacat [6].

Selanjutnya, Serdaroglu dkk. menghitung de- komposisi paket wavelet 2 dimensi dan independent component analysis (ICA) dari citra cacat dan tidak cacat, untuk kemudian dibandingkan hasilnya menggunakan jarak Euclidian. Mereka menemukan bahwa menggunakan gabungan paket wavelet dan ICA dapat meningkatkan hasil deteksi daripada menggunakan wavelet atau ICA saja [7]. Peneliti lain mengajukan penggunaan transformasi wavelet untuk mendeteksi cacat tekstil pada bahan tekstil yang berpola (corak), khususnya untuk tekstil dengan pola Jacquard. Mereka mengusulkan kombinasi antara metode Golden Image Subs-traction (GIS) dan wavelet dan melaporkan bahwa penggabungan keduanya menghasilkan tingkat ke-benaran deteksi yang tinggi [8].

Andika dkk. menggunakan koefisien wavelet aproksimasi dari dekomposisi dua tingkat sebagai fitur. Suatu tekstil dinyatakan cacat jika nilai jarak Euclidian antara koefisien aproksimasi citra masuk- an dan koefisien citra referensi berada di atas nilai ambang yang telah ditentukan. Mereka menggu- nakan lima jenis cacat tekstil dan hasil simulasinya menunjukkan bahwa metode tersebut sesuai untuk mendeteksi citra dengan cacat lubang [9].

Murino dkk. menggunakan histogram dari citra grey-scale, shape descriptors dan cooccurrence matrices untuk memperoleh fitur deteksi cacat tekstil. Studi peneliti ini mengemukakan bahwa fitur histogram dari suatu citra cacat lebih deskriptif dari pada fitur statistic histogram (mean, deviasi standar atau entropy) [10].

\section{METODE}

Penelitian dilaksanakan berbasiskan simulasi sesuai dengan diagram blok metode usulan yang ditunjukkan pada Gambar 1. Citra non-cacat yang digunakan sebagai referensi didekomposisikan dua tingkat dengan wavelet Daubechies (citra non cacat selanjutnya disebut sebagai citra referensi). Kemu-dian, histogram normalisasi dari sub-band aproksimasi dua (LL2) dihitung dan disimpan pada basis data citra. Pada saat suatu citra uji akan dideteksi, citra tersebut mengalami proses yang sama dengan yang dilalui oleh citra referensi.

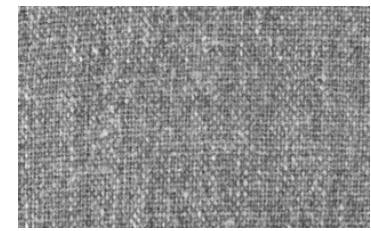

(a) citra acuan

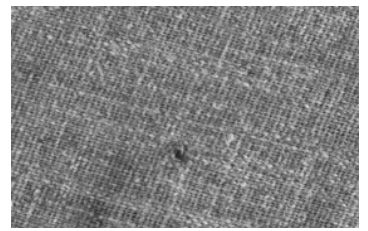

(b) cacat lubang

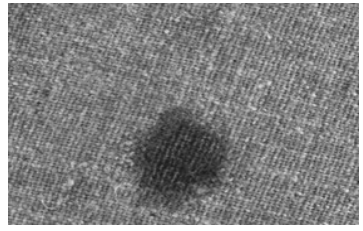

(c) cacat tinta

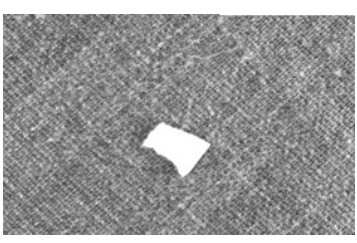

(d) cacat kotoran

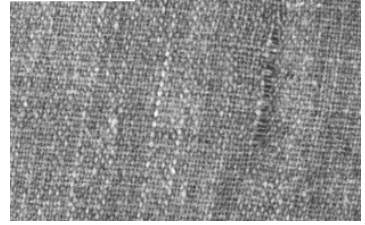

(e) benang lepas

Gambar 2. Contoh citra referensi dan citra cacat yang digunakan pada simulasi 


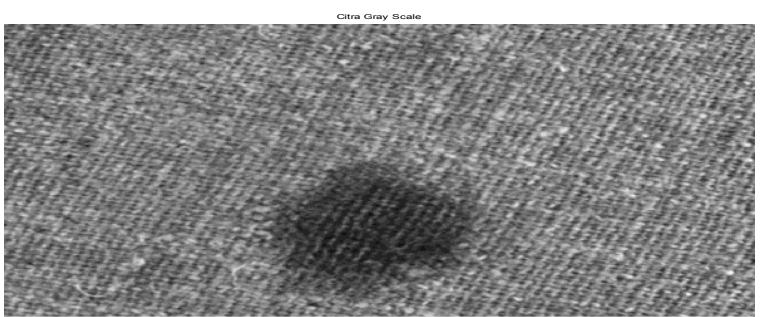

(a) citra asli, ukuran 512x768 piksel.

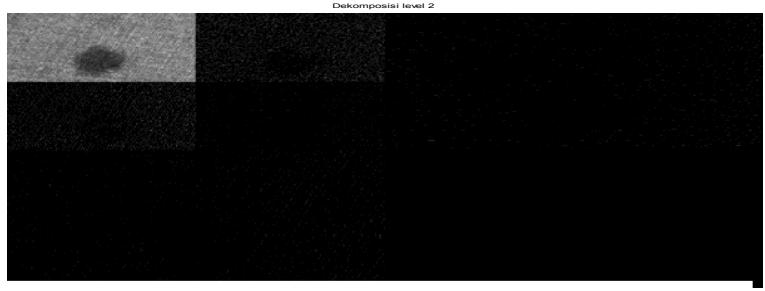

(b) citra setelah dekomposisi wavelet 2 tingkat, LL2 berukuran 128 x192 piksel.

Gambar 3. Ilustrasi dekomposisi wavelet dua tingkat pada citra tekstil

Pengujian kecacatan suatu citra dilakukan dengan menghitung jarak Euclidian antara his-togram citra referensi dan citra uji. Jika jarak citra uji melewati suatu nilai ambang yang telah diten-tukan sebelumnya, citra tersebut dianggap cacat. Jarak Euclidian $D$ antara histogram $h_{q}$ dan $h_{t}$ diformulasikan pada persamaan 1 [11].

$$
D=(q, t)=\sum\left(h_{q}-h_{t}\right)^{2}
$$

Citra tekstil untuk keperluan simulasi dipe-roleh dari basis data "Textile Texture Data-base" (TILDA) versi 1.0, 1996 [2]. Dua puluh lima citra tekstil yang berasal dari jenis yang sama dipilih, terdiri dari 5 citra tidak cacat yang akan dijadikan citra referensi dan 20 citra cacat yang akan dijadikan citra uji. Dua puluh citra cacat terbagi dalam 4 kelompok yaitu 5 citra dengan cacat lubang, 5 citra dengan cacat tinta, 5 citra cacat karena tambahan kotoran berupa penambahan objek putih pada citra asli, dan 5 citra dengan cacat benang lepas. Lokasi kecacatan/kotor- an dari masing-masing citra cacat pada setiap kelompok berbeda-beda. Orientasi tekstur citra pada setiap kelompok juga berbeda-beda.

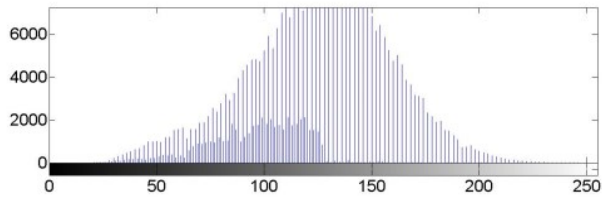

(a) Histogram dari citra asli

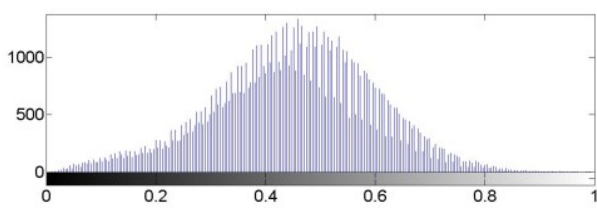

(b) Histogram dari LL1

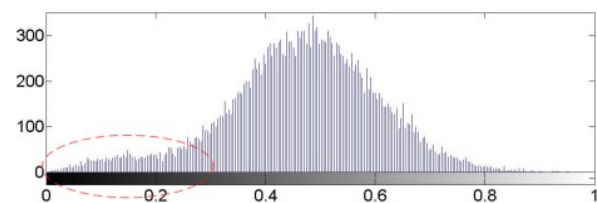

(c) Histogram dari LL2

Gambar 4. Pengaruh dekomposisi wavelet pada bentuk histogram citra asli, koefisisen aproksimasi LL1 dan koefisien aproksimasi LL2.

Masing-masing citra berdimensi 512x768 piksel. Lima con- toh dari citra referensi dan citra cacat yang diguna- kan pada simulasi diperlihatkan pada Gambar 2.

Dekomposisi wavelet dua tingkat mengha- silkan citra koefisien aproksimasi yang lebih kecil ukurannya dibandingkan citra asli. Koefisien aprok-simasi adalah komponen frekuensi rendah dari suatu citra. Apabila koefisien aproksimasi tersebut ditampilkan dengan resolusi yang sesuai, maka akan terlihat seperti citra asli karena kandungan energi terbesar dari citra asli terdapat/dipertahankan pada citra ini.

Pada Gambar 3 diperlihatkan proses dekomposisi wavelet dua tingkat dan penurunan ukuran pikselnya. Pengaruh dekomposisi wavelet pada bentuk histogram citra ditunjukkan pada Gambar 4(a) s.d. (c). Gambar 4(a) adalah histogram dari citra asli dari Gambar 3(a). Gambar 4 (b) dan (c) berturut-turut adalah histogram dari citra LL1 dan LL2 dari Gambar 3 (a). Citra pada Gambar 3 (a) mengandung kotoran tinta, yang seharusnya muncul sebagai sekelompok piksel hitam (piksel dengan nilai rendah) pada histogramnya. Dengan mengamati dan 
membandingkan ketiga histogram pada Gambar 4, didapati bahwa histogram dari LL2 adalah yang paling mewakili penyebaran piksel cit- ra tersebut. Hisogram dari LL2 memiliki penye- baran piksel pada nilai piksel rendah lebih panjang dan jelas dibandingkan dengan histogram lain (dae- rah ini ditandai dengan lingkaran putus-putus).

Untuk mengevaluasi kinerja dari metode usul-an, serangkaian simulasi dilakukan. Histogram LL2 citra referensi pertama dihitung jarak Euclidiannya dengan histogram LL2 semua citra cacat. Selan- jutnya, jarak Euclidian dihitung antara histogram LL2 citra referensi kedua, ketiga, keempat dan kelima dengan histogram LL2 semua citra cacat.

\section{HASIL DAN PEMBAHASAN}

Hasil simulasi berupa jarak Euclidian antara histogram LL2 citra referensi dan histogram LL2 citra cacat diperlihatkan pada Tabel 1. "CA1" adalah singkatan dari "Citra Asli 1", "CA2" adalah singkatan dari "Citra Asli 2" dan seterusnya. CA1", "CA2" dstnya adalah citra referensi. "BL" adalah singkatan dari benang lepas. Pada simulasi ini, nilai ambang ditetapkan secara manual sebesar 0,15. Data jarak yang tercetak dengan huruf tebal adalah jarak yang kurang dari nilai ambang, yang berarti citra dengan nilai tersebut dianggap tidak cacat.

Dari nilai jarak tersebut, analisis dilakukan dalam dua kelompok; (1) nilai jarak antara setiap citra asli dengan semua citra cacat (pada Tabel 1, data ini disusun berdasarkan kolom) dan (2) nilai jarak antara semua citra asli dengan masing-masing jenis cacat tekstil (pada Tabel 1, data ini disusun berdasarkan baris). Pada kelompok pertama; pada saat semua citra cacat dijadikan citra uji terhadap masing-masing citra referensi "CA1", "CA2", "CA3", "CA4" dan "CA5", rate deteksi cacat tekstil berkisar antara 70\% s.d. 90\%. Namun ada satu hal unik pada data tersebut, yaitu ketika "CA1" digu- nakan sebagai citra referensi, semua citra cacat ko- toran memiliki nilai jarak yang sangat dekat dengan citra tersebut (ditunjukkan oleh data bercetak tebal pada kolom ketiga). Berdasarkan metode usulan, ini berarti bahwa histogram dari LL2 tidak dapat mendiskriminasi kecacatan akibat kotoran. Hal ini dapat dijelaskan dengan bantuan Gambar 5.

Tabel 1. Jarak Euclidian antara histogram LL2 citra acuan dengan histogram LL2 citracitra cacat. Data yang dicetak tebal adalah jarak di bawah nilai ambang (0.15).

\begin{tabular}{|c|c|c|c|c|c|c|}
\hline $\begin{array}{c}\text { Kelompok } \\
\text { Cacat }\end{array}$ & $\begin{array}{c}\text { Nama } \\
\text { Cacat }\end{array}$ & CA1 & CA2 & CA3 & CA4 & CA5 \\
\hline \multirow{4}{*}{ Cacat 1 } & bolong 1 & 0.75 & 0.74 & 0.73 & 0.72 & 0.67 \\
\cline { 2 - 7 } & bolong 2 & 0.67 & 0.66 & 0.64 & 0.62 & 0.56 \\
\cline { 2 - 7 } & bolong 3 & 0.77 & 0.76 & 0.75 & 0.74 & 0.69 \\
\cline { 2 - 7 } & bolong 4 & 0.80 & 0.79 & 0.78 & 0.77 & 0.73 \\
\cline { 2 - 7 } & bolong 5 & 0.84 & 0.83 & 0.82 & 0.81 & 0.78 \\
\hline \multirow{4}{*}{ Cacat 2 } & Tinta 1 & 0.97 & 0.97 & 0.97 & 0.97 & 0.96 \\
\cline { 2 - 7 } & Tinta 2 & 0.92 & 0.92 & 0.92 & 0.91 & 0.90 \\
\cline { 2 - 7 } & Tinta 3 & 0.91 & 0.91 & 0.90 & 0.90 & 0.88 \\
\cline { 2 - 7 } & Tinta 4 & 1 & 1 & 1 & 1 & 1 \\
\cline { 2 - 7 } & Tinta 5 & 0.87 & 0.86 & 0.86 & 0.85 & 0.82 \\
\hline & Kotor 1 & $\mathbf{0 . 0 5}$ & $\mathbf{0 . 0 9}$ & $\mathbf{0 . 1 3}$ & 0.19 & 0.40 \\
\cline { 2 - 7 } & Kotor 2 & $\mathbf{0 . 0 5}$ & $\mathbf{0 . 0 9}$ & $\mathbf{0 . 1 4}$ & 0.20 & 0.40 \\
\cline { 2 - 7 } & Kotor 3 & $\mathbf{0 . 1 2}$ & 0.16 & 0.21 & 0.27 & 0.50 \\
\cline { 2 - 7 } & Kotor 4 & $\mathbf{0 . 1 3}$ & 0.17 & 0.23 & 0.29 & 0.51 \\
\cline { 2 - 7 } & Kotor 5 & $\mathbf{0 . 0 5}$ & $\mathbf{0 . 0 9}$ & $\mathbf{0 . 1 3}$ & 0.19 & 0.40 \\
\hline \multirow{4}{*}{ Cacat 4 } & BL 1 & $\mathbf{0 . 0 8}$ & $\mathbf{0 . 0 5}$ & $\mathbf{0 . 0 1}$ & $\mathbf{0 . 0 4}$ & 0.22 \\
\cline { 2 - 7 } & BL 2 & 0.48 & 0.46 & 0.44 & 0.41 & 0.30 \\
\cline { 2 - 7 } & BL 3 & 0.40 & 0.38 & 0.35 & 0.32 & 0.20 \\
\cline { 2 - 7 } & BL 4 & 0.31 & 0.29 & 0.25 & 0.22 & $\mathbf{0 . 0 8}$ \\
\hline & BL 5 & 0.18 & 0.15 & $\mathbf{0 . 1 1}$ & $\mathbf{0 . 0 7}$ & $\mathbf{0 . 0 9}$ \\
\hline
\end{tabular}




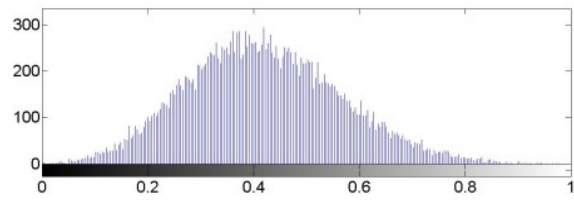

(a) Histogram LL2 dari "CA1"

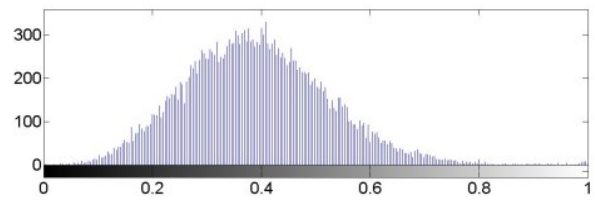

(b) Histogram LL2 dari citra kotor 1

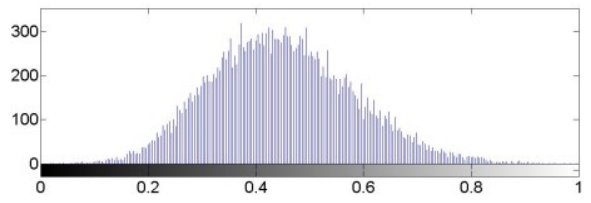

(c) Histogram LL2 dari citra benang lepas 1

Gambar 5. Bentuk histogram LL2 dari "CA1", citra kotor 1 dan benang lepas 1 .

Gambar 5(a) dan (b) menunjukkan histogram LL2 dari "CA1" dan salah satu citra kotor, yaitu citra kotor 1. Bentuk kedua histogram tersebut terlihat hampir kongruen. Hal ini menyebabkan jarak diantara keduanya menjadi kecil, yaitu 0.05 . sehingga citra kotor 1 dianggap tidak cacat.

Pada kelompok kedua; untuk kelompok citra cacat lubang dan tinta, rate deteksi sebesar $100 \%$ berhasil dicapai. Ini berarti semua citra cacat berhasil dideteksi dengan benar. Seba- liknya, rate deteksi citra cacat kotoran dan benang lepas lebih rendah, yaitu masing-masing $56 \%$ dan $68 \%$. Analisis langsung dari hasil ini adalah, bahwa histogram LL2 dari citra cacat kotor dan benang lepas sangat mirip dengan histogram LL2 dari citra referensi. Histogram LL2 dari citra benang lepas 1 diperlihatkan pada Gambar 5(c).

Pembahasan selanjutnya akan menjelaskan alasan tingginya nilai rate deteksi citra cacat tinta, cacat lubang dan cacat benang lepas dibandingkan citra cacat kotoran. Gambar 6 menunjukkan perubahan gradasi keabuan citra LL1 dan LL2 akibat dekomposisi wavelet dan histogram ternormalisasi dari masing-maing citra tersebut, untuk citra cacat tinta. Citra LL1 dan LL2 adalah citra yang diperoleh dengan proses low-pass filtering. Proses low-pass filtering pada dekompo- sisi wavelet mengakibatkan membesarnya inteterval nilai piksel pada pada citra. Jika pada citra asli, interval nilai piksel berada antara 0 s.d. 255, pada LL1, interval nilai piksel dapat berada antara 50 s.d. 500,

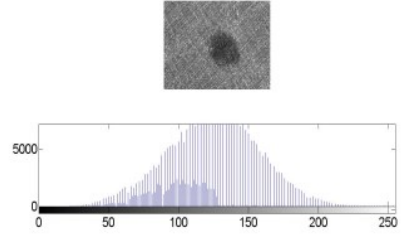

(a) Citra dan histogram citra asli

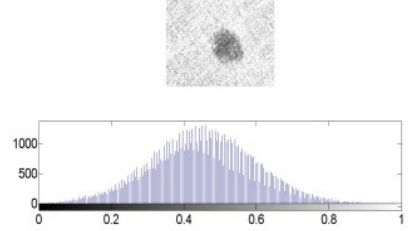

(b) Citra dan histogram LL1

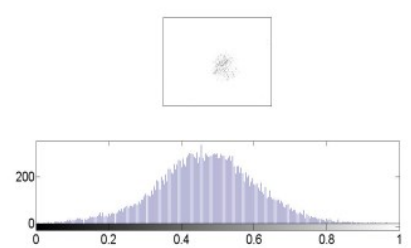

(c) citra dan histogram LL2

Gambar 6. Perubahan gradasi citra LL1 dan L12 akibat dekomposisi wavelet dan bentuk masing-masing histogramnya berupa cacat tinta.

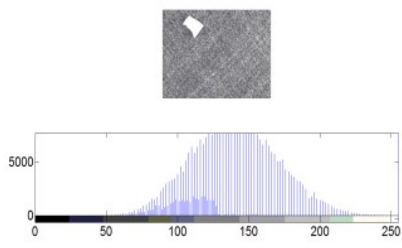

(a) Citra dan histogram citra asli

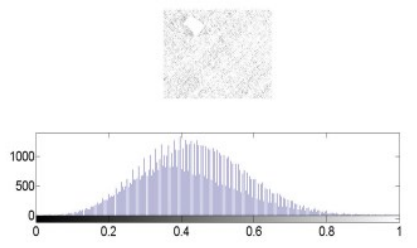

(b) Citra dan histogram LL1

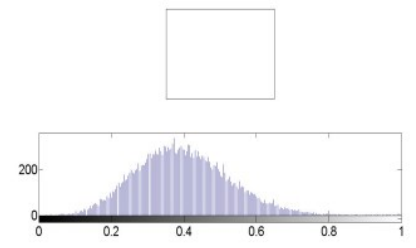

(c) citra dan histogram LL2

Gambar 7. Perubahan gradasi citra LL1 dan LL2 akibat dekomposisi wavelet dan bentuk masing-masing histogram normalisasinya pada citra dengan cacat kotoran berupa tambahan objek berwarna putih. 
dan pada LL2 interval ini membesar lagi. Sebagai akibatnya, citra-citra terlihat lebih putih (pudar), kecuali proses normalisasi nilai piksel ke interval 0 s.d. 255 dilakukan. Pemudaran seperti ini tidak menghilangkan informasi kecacatan dari citra cacat tinta, caat lubang dan sebagian cacat benang lepas dari LL2-nya. Hal ini bisa dilihat pada bagian citra LL2 dari Gambar 6. Pada Gambar 6, nilai piksel citra LL1 dan LL2 tidak dinormalisasi, dan resolusinya tidak disesuaikan dengan yang seharusnya, untuk mendapatkan ilustrasi yang lebih jelas.

Sebaliknya, sifat pemudaran ini kurang sesuai untuk citra yang mengandung objek berwarna putih, seperti ditunjukkan pada Gambar 7. Objek putih pada citra LL2 dari citra cacat kotoran, tidak bisa dibedakan dari latarnya yang telah memutih.

Selanjutnya, jika ditinjau dari histogramnya, histogram LL2 dari citra cacat tinta memiliki jumlah kemunculan piksel pada bagian awal yaitu pada interval 0 s.d. 0.2 , yang berhubungan dengan noktah tinta. Seperti telah dibahas pada sub-bab "Metode", histogram LL2 pada jenis cacat ini lebih informatif jika dibandingkan dengan histogram asli atau pun histogram LL1. Sebaliknya, histogram LL2 dari citra cacat kotoran, tidak mengandung informasi yang khusus. Histogram tersebut tidak mengandung kemunculan piksel berwarna putih pada interval $0.8 \mathrm{~s}$. d. 1, yang diasumsikan ada, jika kotorannya berwarna putih.

\section{KESIMPULAN}

Suatu metode deteksi cacat tekstil berbasis histogram dari citra aproksimasi wavelet dua tingkat telah dipaparkan pada makalah ini. Empat kelompok citra cacat digunakan pada simulasi untuk mengetahui rate deteksi metode usulan terhadap masingmasing kelompok citra. Parameter evaluasi yang digunakan adalah jarak Euclidian antara histogram LL2 citra asli dengan histogram LL2 citra cacat. Ditemukan bahwa metode usulan mencapai rate deteksi sebesar 100\% untuk citra cacat lubang dan cacat tinta, dimana terdapat noktah gelap pada lokasi yang bervariasi pada citra cacat.

\section{DAFTAR PUSTAKA}

[1] L. Bissi et.al., "Automated defect detection in uniform and structured fabric using Gabor filters and PCA", J. Vis. Commun. Image R., Vol. 24, pp. 838-845, 2013

[2].Tilda Database, diakses di http://lmb.informatik.uni-

freiburg.de/resources/datasets/tilda.en.html, Februari 2013.

[3] H. Y. T. Ngan et. al., "Automated fabric defect detection- A Review", Image and Vision Computing, Vol. 29, pp. 442-458, 2011.

[4] Chun-Lin, Liu, "A Tutorial of the wavelet transform", February 23, 2010, diakses pada 20 Februari 2014.

[5] S. Arivazhagan et. al., "Fault segmentation in fabric images using Gabor wavelet transform", Machine Vision Applications, vol. 16, No. 6, pp. 356-363, 2006.

[6] Chi-ho Chan, et. al., "Fabric defect detection by Fourier analysis", IEEE Transactions on Industry Applications, Vol. 36, No. 5, pp. 1267-1276, 2000.

[7] A. Serdaroglu, et.al., Defect detection in textile fabric images using wavelet transforms and independent component analysis", Pattern Recognition and Image Analysis, Vol. 16, No. 1, pp. 61-64, 2004.

[8] H. Y. T. Ngan et. al., "Wavelet based methodson pattern fabric defect detection", Pattern recognition, Vol. 38, pp. 559-576, 2005.

[9] Andika, Fitri Arnia dan Khairul Munadi, "De- teksi cacat tekstil menggunakan fitur koefisien aproksimasi wavelet dan euclidean distance," karya ilmiah Jurusan Teknik Elektro, Universitas Syiah Kuala, 2013.

[10] V. Murino, et.al., "Statistical classification of raw textile defects", Proc. of the 17th International Conference on Pattern Recognition", 2004.

[11] V. Castelli, "Image Databases: Search and Retieval of Digital Imagery", John Wiley and Sons, 2002. 


\section{Biodata penulis}

Fitri Arnia memperoleh gelar Sarjana Teknik dari Universitas Sumatera Utara (USU), Medan pada tahun 1997. Pendidikan tingkat master dan doktoral diselesaikannya pada Universsity of New South Wales (UNSW), Sydney, Australia dan Tokyo Metropolitan University, Jepang berturut-turut pada tahun 2004 dan 2008. Dia bekerja sebagai staf pengajar pada Jurusan Teknik Elektro, Fakultas Teknik, Universitas Syiah Kuala sejak tahun 1999. Dr. Arnia adalah anggota IEEE dan IAENG. Bidang penelitiannya meliputi pengolahan sinyal, citra dan multimedia digital

Andika Saputra dilahirkan di Ujung Tengah, pada tahun 1989 dan memperoleh gelar Sarjana Teknik pada Jurusan Teknik Elektro Universitas Syiah Kuala Pada tahun 2014.
Khairul Munadi memperoleh gelar Sarjana Teknik dari Institut Teknologi Sepuluh Nopember Surabaya, Indonesia, pada tahun 1996, dan gelar master dan doktoral dari Tokyo Metropolitan University (TMU), Jepang, pada tahun 2004 dan 2007. Dari tahun 1996 sampai dengan 1999, dia bekerja sebagai system engineer di Alcatel Indonesia. Sejak tahun 1999, dia bergabung dengan Universitas Syiah Kuala, sebagai tenaga pengajar pada Jurusan Teknik Elektro. Dr. Munadi adalah peneliti tamu pada Information and Communication Systems Engineering, Faculty of System Design, TMU, Jepang, dari Maret 2007 sampai dengan Maret 2008. Minat penelitiannya meliputi pengolahan sinyal multimedia dan telekomunikasi 